
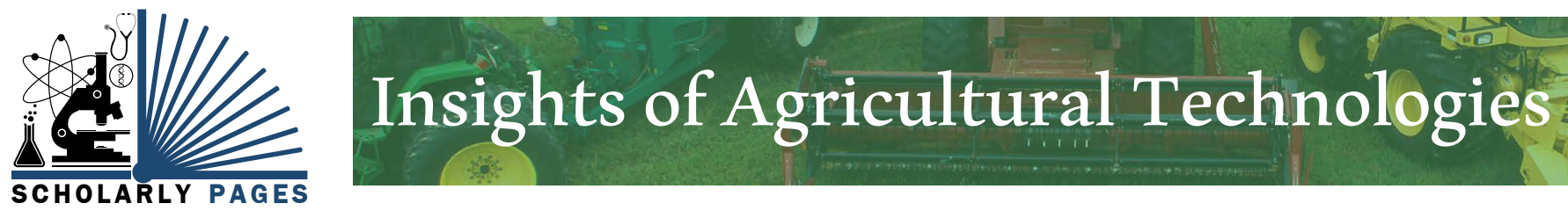

\title{
Identification and Content Detection of Citrus Juice Based on Nanoparticle-DNA Technology
}

\author{
Teng Zuo', Yuan Jing ${ }^{1}$ and Yu Jie ${ }^{1,2^{*}}$ \\ ${ }^{1}$ College of Horticulture and Landscape Architecture, Southwest University, China \\ ${ }^{2}$ Key Laboratory of Horticulture for Southern Mountainous Regions, Ministry of Education, China
}

\begin{abstract}
This experiment detected the luminescence intensity of the Nanoparticles of citrus juice and calculated its DNA concentration using the Nanoparticles-DNA technology, which can be used to determine the authenticity of citrus juice and the test of DNA concentration. The results showed that the linear equation between the concentration of DNA and the intensity of the luminescence was $y=-0.0003 x+2.1454$, which presented a good linear relation $\left(R^{2}=0.999\right)$ in the range of $5.0 \sim 780$ $\mathrm{ug} / \mathrm{mL}$. The sample DNA concentration was calculated based on the linear equation, and the detection value was the same as that of nucleic acid protein tester. The results of the study provide a new, simple and quick method for the determination of DNA concentration.
\end{abstract}

Keywords

Nanoparticles, DNA, Citrus juice, Identification

\section{Introduction}

Citrus fruit juice products are important in people's daily drink, and food quality security problem is one of the important subjects of human health. Rapid and accurate identification of fruit juice is still a scientific problem to be settled. Citrus juice is influenced by processing capacity, product quality, production and price of raw material. And the raw materials are affected by natural conditions, pests, and so on, and that makes the international market $50 \%-80 \%$ of the citrus juice to be part of the problem [1]. In the market, there is a phenomenon that the actual concentration of fruit juice is not in accordance with the indicated concentration in addition to the fraud of adding pigments in the juice or even juice composed solely of pigments. There are three methods for the identification of citrus fruit juice: Sensory discrimination, physicochemical and molecular biology techniques. These detection methods often rely on a certain characteristic component, special property, or special instruments to distinguish the citrus fruit juice. DNA is the carrier of the genetic information of the organism, and the genetic information determines the nature of the organism [2]. The authority and scientificity of DNA based molecular identification have made the technology widely used in the field of juice authenticity identification. DNA based molecular identification includes conventional molecular techniques and emerging barcoding techniques. Herbst [3] used conventional molecular techniques to identify blueberry and cranberries, and successfully detected blueberries from fruits such as apples and pears. Bruni [4] used the emerging barcode technology to identify apple, elderberry and tomato plants from mixed juices.

Nanoparticles-DNA technology is a new molecular identification method based on DNA. Unlike conventional molecular techniques and emerging barcode technology, this method is a simple, fast and low-cost method of identification. Conventional molecular techniques and emerging barcode technology are more about

*Corresponding author: Dr. Yu Jie, College of Horticulture and Landscape Architecture, Southwest University; Key Laboratory of Horticulture for Southern Mountainous Regions, Ministry of Education, Chongqing, China

Accepted: September 20, 2018;

Published online: September 22, 2018

Citation: Zuo T, Jing Y, Jie Y (2018) Identification and Content Detection of Citrus Juice Based on Nanoparticle-DNA Technology. Insights Agric Technol 1(1):7-10

Copyright: @ 2018 Zuo T, et al. This is an open-access article distributed under the terms of the Creative Commons Attribution License, which permits unrestricted use, distribution, and reproduction in any medium, provided the original author and source are credited. 


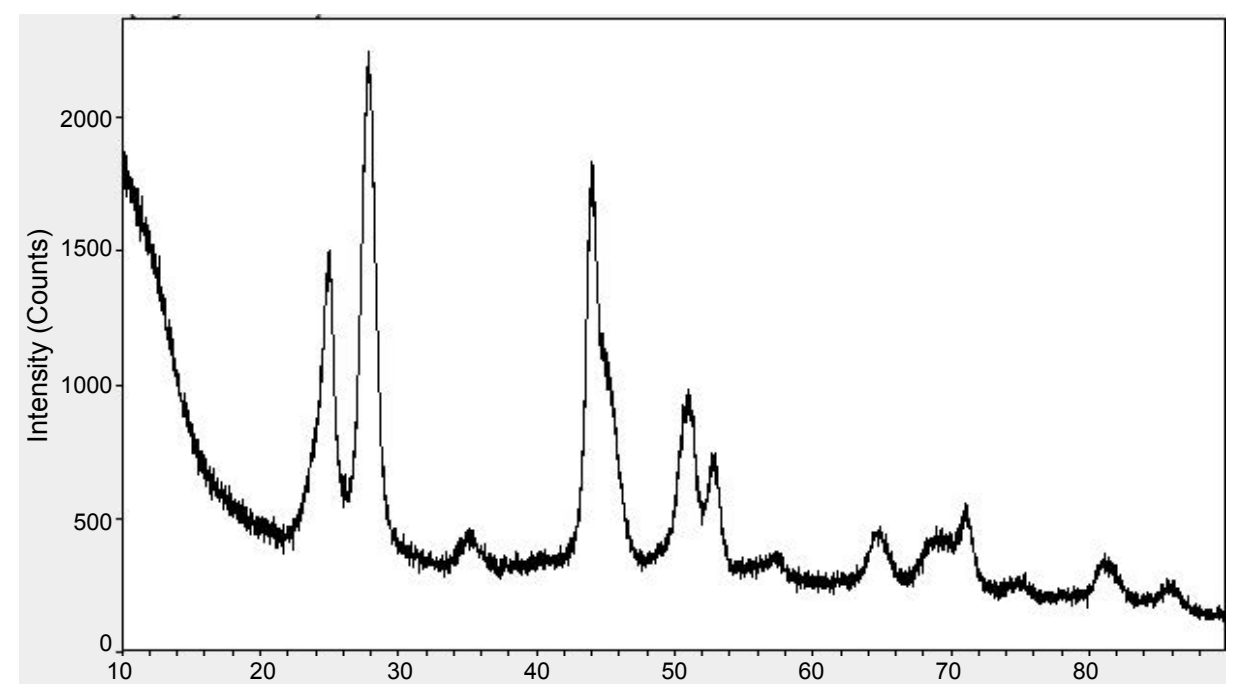

Figure 1: X-ray diffraction map.

whether the source of the DNA in fruit juice comes from the fruit. This method was studied on citrus juice, and the quality of citrus juice was determined by the reaction of luminescent nanoparticles and citrus juice. $\mathrm{Yu}$ yongli [5] have studied a good, strong and luminous DPA-LaF3: $\mathrm{Tb}$ nanoparticles. The nanoparticles are formed from a combination of a pyridine dicarboxylic acid (DPA) with a weakly luminous nanoparticle (LaF3: Tb nanoparticles). DPA-LaF3: $\mathrm{Tb}$ is a luminous nanoparticle, and its luminous energy comes from DPA. After DPA-LaF3: Tb nanoparticle is mixed with fruit juice DNA, DNA embedded into DPA makes DPA leave LaF3: Tb nanoparticle, leading to the luminescence quenching of DPA-LaF3: $\mathrm{Tb}$ nanoparticle. The higher the DNA concentration, the lower the luminescence intensity of LaF3: Tb nanoparticles. For nanoparticles-DNA binding technology, gold nanoparticles are also used for detection of DNA, and Tan Bisheng [6] mentioned that gold nanoparticles can be used for optical detection and electrochemical detection when combined with DNA. Mirkin [7] used optical method to detect DNA, and the detection sensitivity of colorimetric method reached the level of $10 \mathrm{~mol}$ (10-14 mol) oligonucleotide [8], and the solution color was significantly changed from red to blue. The DNA sequence of 406-base pairs of human cells was successfully detected by Authier [9] electrochemical method. This experiment explores the linear relationship between the concentration of DNA and the luminescence intensity of the solution. A certain amount of DNA solution reacts with nanoparticles. In this experiment, a certain amount of DNA solution was reacted with the nanoparticles, and then the luminous intensity of the solution was determined. The concentration of juice DNA can be calculated by bringing the luminous value into the standard curve. Finally, the purpose of identifying the quality of citrus juice was proposed.

\section{Experiments}

We have selected the fresh juice A, six kinds of common citrus fruit juice drinks (B, C, D, E, F, G) as the materials in this experiment. The improved $\mathrm{CTAB}$ method was adopted to extract the DNA in citrus juice [10], and the DNA was preserved at $-20^{\circ} \mathrm{C}$. DPA-LaF3: Tb nanoparticles were synthesized by hydrothermal method [5].

Add $1 \mathrm{ml}$ of $4.2 \times 10^{-3} \mathrm{mM}$ DPA-LaF3: Tb particle solution and $0.8 \mathrm{ml}$ of $1.5 \mathrm{M} \mathrm{NaCl}$ solution to the test tube, then add $5 \sim 780 \mathrm{uL} 100 \mathrm{ug} / \mathrm{mL}$ Herring sperm DNA standard solution. Finally, add Tris-HCL buffer solution (pH 8) to $6.00 \mathrm{ml}$, and shake well. After $15 \mathrm{~min}$, the luminescence intensity of the solution was measured at 546 $\mathrm{nm}$. The measured luminous intensity was brought into the standard curve to calculate the concentration $\mathrm{C}$ of dilute solution. The synthesized nanoparticles were sent to Beijing zhongke baike technology services co. LTD, which are characterized by X-ray diffraction (XRD) and Transmission electron microscope (TEM).

\section{Results and Discussions}

\section{Characterization of nanoparticles}

Figure 1 is the XRD map of DPA-LaF3: Tb nanoparticles. There are no stray peaks in the figure, indicating that a single phase six crystal system LaF3 has been synthesized. There are 5 obvious diffraction peaks $\left(25.0^{\circ}\right.$, $\left.44.0^{\circ}, 27.60^{\circ}, 50.80^{\circ}, 52.80^{\circ}\right)$. According to the position of 5 diffraction peaks, the average grain size of the particle is $14 \mathrm{~nm}$ by using the Scherrer equation.

Figure 2 shows the TEM map of DPA-LaF3: Tb nanoparticles. The dispersion of the particles is good, the particle size is uniform, the shape of the particle is spherical, and the calculated particle size is $15 \mathrm{~nm}$, which is basically the same as the $14 \mathrm{~nm}$ of XRD. 


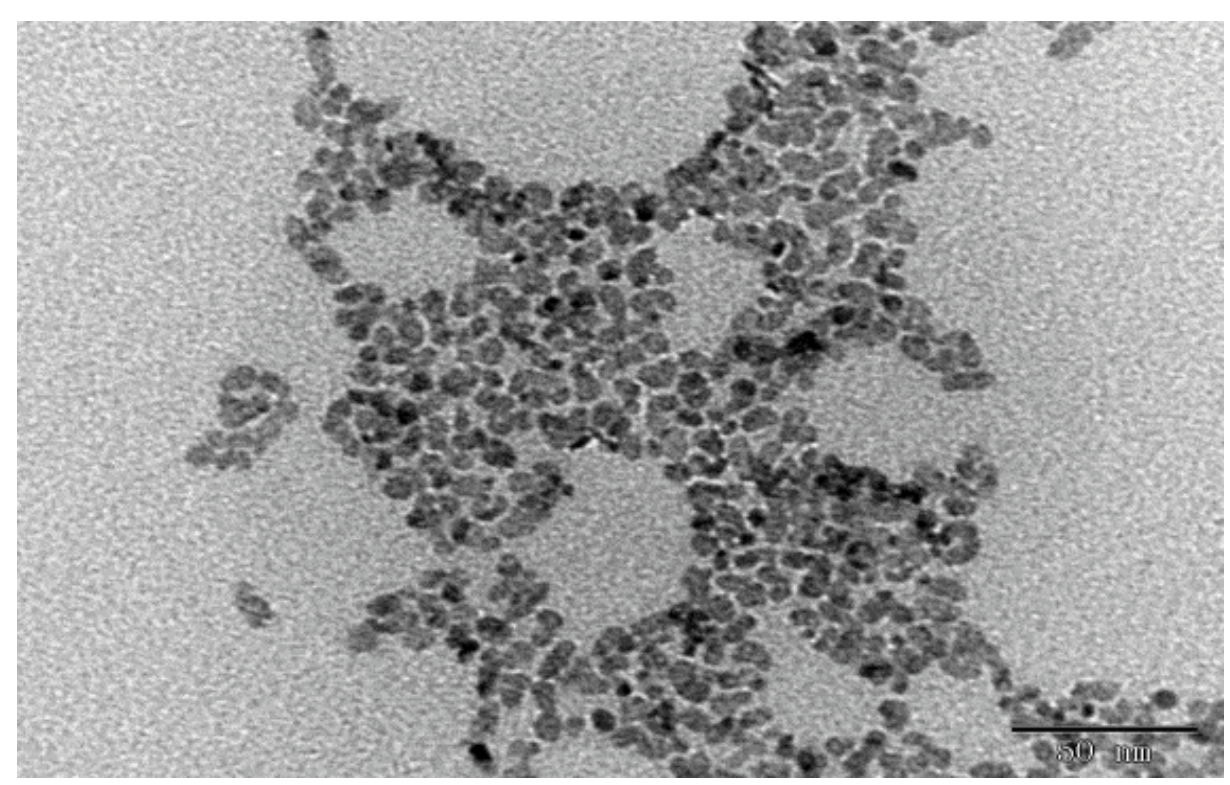

Figure 2: Transmission electron microscope map.

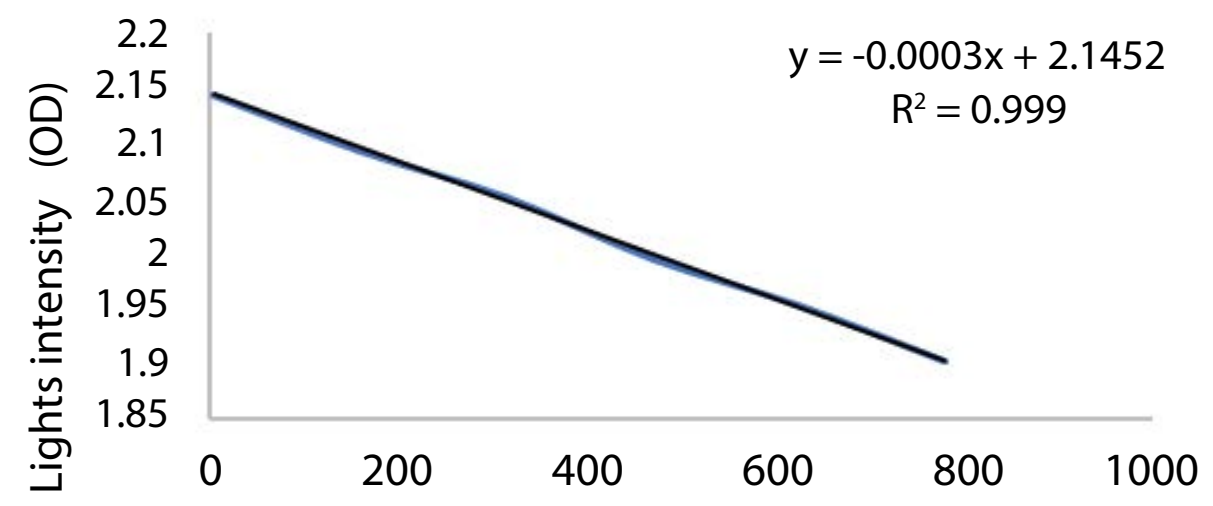

DNA contents $(\mathrm{ug} / \mathrm{mL})$

Figure 3: The standard curve.

\section{Standard curve prepared}

The standard curve was performed using herring sperm DNA as standard (Sigma company). The results are shown in Figure 3.

The concentration of DNA is reported on the X axis, the intensity of the luminescence is reported on the $\mathrm{Y}$ axis, and the regression equation is obtained by drawing the standard curve: $\mathrm{Y}=-0.0003 \mathrm{x}+2.1452, \mathrm{R}^{2}=0.999$. The results showed that the Linear relationship between $5 \sim 780 \mathrm{ug} / \mathrm{mL}$ was good.

\section{Determination of DNA content of 6 kinds of cit- rus juice}

After its extraction by a modified CTAB method, the DNA concentration from seven citrus juices of $A, B$, $\mathrm{C}, \mathrm{D}, \mathrm{E}, \mathrm{F}$ and $\mathrm{G}$ was determined by using two methods. The first one is the detection of the concentration of the ND2000 ultra micro-nucleic acid protein tester, and the other is the detection of the concentration by the Nanoparticles-DNA technology. The results are shown in Table 1.

We can see from Table 1 that there is no significant difference between the results detected by two different techniques. The method was able to accurately detect the amount of DNA in citrus juice. Sample A is freshly squeezed juice, and its DNA content is significantly higher than that of ordinary orange juice. The sample $\mathrm{D}$ and $\mathrm{E}$ are all $100 \%$ beverages, but in the process of processing, the concentration is significantly lower than that of freshly squeezed juice because of the degradation of DNA due to high temperature. Samples B, C and F are cheaper juice with different concentrations, and their DNA content is significantly lower than that of sample $\mathrm{A}, \mathrm{D}$ and $\mathrm{E}$. The sample $\mathrm{G}$ is pigment drink, which con- 
Citation: Zuo T, Jing Y, Jie Y (2018) Identification and Content Detection of Citrus Juice Based on NanoparticleDNA Technology. Insights Agric Technol 1(1):7-10

Table 1: The comparison of DNA concentration measurements of citrus juice by nucleic acid protein tester and Nano-DNA technology.

\begin{tabular}{|l|l|l|l|}
\hline Sample & $\begin{array}{l}\text { Solution luminous } \\
\text { intensity (OD) }\end{array}$ & $\begin{array}{l}\text { The concentration with nanoparticles- } \\
\text { DNA technology }(\mathbf{u g} / \mathbf{m L})\end{array}$ & $\begin{array}{l}\text { The concentration with nucleic acid } \\
\text { protein tester }(\mathbf{u g} / \mathbf{m L})\end{array}$ \\
\hline A & 2.09504 & 167.2 & 167.1 \\
\hline B & 2.14226 & 9.8 & 9.7 \\
\hline C & 2.14034 & 16.2 & 16.1 \\
\hline D & 2.12558 & 65.4 & 65.2 \\
\hline E & 2.12705 & 60.5 & 60.6 \\
\hline F & 2.14031 & 16.3 & 16.2 \\
\hline G & 2.14555 & -1.18 & 0.2 \\
\hline
\end{tabular}

tains no DNA, since the concentration is below the linear range of $5 \mathrm{ug} / \mathrm{mL}$, so it is not accurate to calculate the absorbance value of the nanoparticle, so it is negative in the table.

\section{Conclusions}

Nanoparticles-DNA technology has simple, fast characteristics compared with conventional DNA molecule technology and emerging barcode technology.

DPA-LaF3: Tb nanoparticles can react with any DNA, without primer binding. Therefore, it can also be used to identify the authenticity of other fruit juice, which has a broad prospect of development.

\section{Acknowledgments}

This work was financially supported by Chongqing basic and frontier research project (CSTC2013JCYJA80002).

\section{References}

1. Zhou KL, YE YM (2010) Chinese fruit tree-citrus rolls. China Forestry Publishing House, 62-130, Beijing.

2. Li MG, Wu YJ, Yang YG (2016) Progress in authentication technologies for berry juice. Food Science 37: 243-250.
3. Herbst N, Wilson T, Klein J, et al. (2014) Detection of cranberry and blueberry (Vaccinium sp.) DNA by PCR amplification of the MatK gene. The Faseb Journal 28: 386.

4. Bruni I, De Mattia F, Galimberti A, et al. (2010) Identification of poisonous plants by DNA barcoding approach. Int $\mathrm{J}$ Legal Med 124: 595-603.

5. Yu YL, Wang LM, Xu Shu-Kun (2013) Synthesis of dipicolinate sensitized LaF3: Tb nanoparticles and their application in the determination of DNA. Chemical Journal of Chinese Universities 34: 1617-1622.

6. Tan BS, Cao XH, Mo ZH (2003) Gold nanoparticles preparation and application in DNA detection. Journal of Chongqing University 26: 1-5.

7. James J Storhoff, Anne A Lazarides, Robert C Mucic, et al. (2000) What controls the optical properties of DNA-linked gold nanoparticle assemblies? J Am Chem Soc 122: 4640-4650.

8. Collier CP, Vossmeyer T, Heath JR (1998) Nanocrystal superlattices. Annu Rev of Phys Chem 49: 371-404.

9. Authier L, Grossiord C, Brossier D (2001) Gold nanoparticle-based quantitative electrochemical detection of amplified human cytomegalovirus DNA using disposable microband electrodes. Anal Chem 73: 4450-4456.

10. Liu WH, Xu WT, Shang Y (2012) Comparison on the extraction method of DNA and study on the biotechnological detection of orange component in juice. Chinese Journal of Food Science 12: 195-201. 